\title{
Álvaro Cubillo de Aragón, El señor de Noches Buenas, ed. Francisco Domínguez Matito, Kassel, Reichenberger, 2020, 269 pp. ISBN: 978-3-967280-15-9
}

\section{Victoriano Roncero López}

Stony Brook University

ESTADOS UNIDOS

victoriano.roncero-lopez@stonybrook.edu

[Hipogrifo, (issn: 2328-1308), 9.1, 2021, pp. 1385-1389]

Recibido: 11-04-2021 / Aceptado: 21-04-2021

DOI: http://dx.doi.org/10.13035/H.2021.09.01.79

Las ediciones y estudios del teatro español del Siglo de Oro han conocido un importante auge durante las últimas décadas; ya sean los autores canónicos (aquí podemos destacar la publicación de los autos sacramentales completos de Calderón a punto de concluir), o los menos «populares» (entre los que destacamos las ediciones de comedias de Pérez de Montalbán o de Rojas Zorrilla, por citar las más avanzadas) el lector y el especialista en la dramaturgia áurea tienen a su disposición ediciones cuidadas ecdóticamente y estudios reveladores que nos permiten un más profundo conocimiento de un fenómeno tan importante como es el del teatro español del siglo XVII.

Uno de estos autores poco conocidos y que merecen mucha más atención crítica de la recibida es, sin duda, el almagreño Álvaro Cubillo de Aragón, «uno de los más interesantes y singulares dramaturgos» de la escuela calderoniana (p. IX). Su recuperación para el canon dramático áureo se inició a principios del siglo XX gracias a la labor de dos importantes especialistas: Emilio Cotarelo y Mori y Ángel Valbuena Prat'. Los estudios y ediciones de estos dos grandes conocedores del teatro clásico español no tuvieron un impacto importante en estudiosos posteriores que continuaron dejando a un lado las comedias del dramaturgo almagreño. Ciertamente hubo excepciones notables como la bibliografía de Profeti-Zancanari ${ }^{2}$

1. Emilio Cotarelo y Mori, «Dramáticos españoles del siglo xVII. Álvaro Cubillo de Aragón», Boletín de la Real Academia Española, V, 1918, pp. 3-23 y 241-280.

2. María Grazia Profeti y Umile Maria Zancanari, Per una bibliografia di Álvaro Cubillo de Aragón, Verona, Universitá degli Studi di Verona, Istituto di Lingue e Letterature Straniere, 1983. 
o el estudio de Shirley Whitaker ${ }^{3}$, en el contexto teatral, y el de Marie-France Schmidt ${ }^{4}$, en el de las fábulas políticas incluidas en El enano de las Musas. Un hito fundamental en el reconocimiento del teatro del almagreño lo ha supuesto la labor del profesor Francisco Domínguez Matito, que inició el proyecto de edición de las comedias y autos sacramentales completos allá por el año 2012, proyecto ahora revitalizado con la publicación de nuevas comedias en la prestigiosa Edition Reichenberger, cuya primera muestra es esta nueva edición de uno de los textos claves y más reconocidos de la dramaturgia «cubillesca»: El señor de las Noches Buenas. Esta comedia había sido ya editada en 1928 por el ya mencionado Valbuena Prat en la meritoria colección de «Los clásicos olvidados», junto con Las muñecas de Marcela. Este trabajo, sin embargo, no responde a los criterios de rigurosidad de nuestra época, por lo que era necesaria su revisión, «respondiendo a las exigencias de la metodología ecdótica más moderna» (p. XI) y a su actualización crítica, objetivos ambos que, como vamos a ver, cumple a la perfección el texto editado por el profesor Domínguez Matito.

La introducción se abre con unos breves apuntes biográficos, en los que se aclara el lugar de nacimiento de Cubillo, del que sabíamos que pertenecía a una familia morisca, y a quien desde Vélez de Guevara y Nicolás Antonio, se le atribuía un origen granadino, aunque ha sido recientemente demostrado que vino al mundo en Almagro, donde recibió el bautizo el 10 de noviembre de 1590. El editor destaca los principales datos de su vida y resalta que su origen morisco es clave para interpretar ciertos rasgos de su obra literaria: su delectación en temas árabes y cierta ironía «que revela el atavismo moro, bajo el ropaje del caballero católico» (p. 7).

A continuación, se entra ya en el análisis de El señor de Noches Buenas, que apareció publicada por primera vez en Madrid en Flores de las mejores doce comedias de los mayores ingenios de España, con atribución a Antonio Hurtado de Mendoza, por lo que el almagreño decidió incorporarla en su El enano de las Musas, impreso en Madrid en 1654, aunque con fecha de aprobación de 1652, para reivindicar su autoría. Domínguez Matito recuerda que conservamos datos que sitúan su primera representación en Granada en una fecha incierta, e inmediatamente después lo fue en Madrid por la compañía de Roque de Figueroa en junio de 1634 y en abril de 1635. Estos datos son importantes para fijar la posible fecha de escritura de la obra junto con una referencia interna: la alusión a la muerte del rey sueco Gustavo II Adolfo acaecida el 16 de noviembre de 1632. Por todo ello, el editor sitúa la composición de la obra entre 1630 y 1632.

El segundo apartado de la introducción se centra en la cuestión genérica. El editor reconoce la cercanía temática y argumental de El señor con otra de sus comedias El invisible príncipe del Baúl, aunque en esta última abundan más los rasgos de comicidad. Domínguez Matito recoge las opiniones críticas que insertaron esta obra en el género de la comedia de figurón, de la comedia de costumbres y de la comedia de carácter, y pone de relieve su relación con el de capa y espada,

3. Shirley B. Whitaker, The Dramatic Works of Álvaro Cubillo de Aragón, Chapel Hill, North Carolina Studies in the Romance Languages and Literatures, 1975.

4. Marie-France Schmidt, «Dos fábulas políticas de Álvaro Cubillo de Aragón», Criticón, 19, 1982, pp. 5-81. 
para concluir que se trata del «eslabón insoslayable en el proceso que conduce a la fijación de un personaje de comedia y a la cristalización de un género teatral que, partiendo de la de capa y espada, irá adquiriendo en el transcurso del XVII sus propios perfiles» (p. 21). Por tanto, la considera, creo que acertadamente, en el género de «comedia urbana» o «comedia de capa y espada» con sus rasgos definitorios: funcionalidad de las unidades de tiempo y espacio; cierta atmósfera de inverosimilitud de la trama amorosa; generalización de la comicidad de nobles y criados; relevancia de algunos motivos como el fracaso del matrimonio y el valor del dinero.

La temática de la comedia se centra en el conflicto entre dos hermanos, que, como señala el editor, es un tema repetido en varias comedias de Cubillo. Domínguez Matito lleva a cabo un detenido análisis de ese conflicto fraternal entre el primogénito-mayorazgo (el Marqués) y el segundón (Enrique), conflicto que se fundamenta en la envidia y que tiene como base, como es típico en la comedia de capa y espada, el amor (aquí debemos recordar La dama duende calderoniana, por ejemplo). Otro tema interesante relacionado con el amor, y que también tiene referentes múltiples en el género, es la defensa del derecho de la mujer (la dama) a elegir marido. Un aspecto importante del estudio de este apartado tiene que ver con los mecanismos de la comicidad, que, como muy bien señala Domínguez Matito, en esta comedia están puestos al servicio de una intencionalidad que va más allá del mero entretenimiento.

La fijación de las fuentes en un texto dramático áureo se enfrenta a la dificultad de señalar qué obra pudo ser aquella en la que se basó el autor para la redacción de su texto. El señor no constituye una excepción. El filólogo de la Universidad de La Rioja expone la opinión de los estudiosos anteriores que llegaron a la conclusión de que Cubillo se basó en Las flores de don Juan, de Lope de Vega, para crear su comedia: el espacio dramático, la caracterización de los personajes masculinos principales; el enfrentamiento entre hermanos; la crítica al mayorazgo y el destierro a Flandes; los afectos entre segundones y sus criados; las prevenciones femeninas para la elección del marido: todos estos rasgos fueron señalados por los críticos anteriores para establecer la deuda del almagreño con la comedia del Fénix de los Ingenios. Sin embargo, acierta el editor cuando afirma que estos motivos presentan un sentido distinto en la obra del almagreño y que la estructuración dramática se aleja mucho de la de su hipotético modelo; así, por ejemplo, recuerda que la obra de Lope tiene treinta personajes frente a los nueve de su pretendido continuador. También confronta la dispersión argumental y los elementos gratuitos de la comedia lopesca con la unidad de tema, de acción, de tiempo y de espacio de la de Cubillo.

Tras el imprescindible resumen del argumento, Domínguez Matito dedica unas esclarecedoras y profundas páginas al estudio de los personajes: dos galanes (Enrique y Leonardo); dos damas (Porcia y Dorotea); dos criados (Roberto y Copete, que forma la tópica contrapareja con Aldonza) y el padre de la novia. Por tanto, como muy bien, señala el editor, el dramaturgo almagreño siguió el modelo de la comedia de capa y espada instaurado por Lope y Calderón. Quizás el personaje más interesante desde el punto de vista teatral $-y$ a él le dedica el estudioso un interesante análisis - sea el Marqués. El filólogo de la Universidad de La Rioja re- 
salta sus características de personaje ridículamente egoísta y avaricioso, rayano con la necedad, envidioso y cobarde. Destaca también en este apartado su cercanía con el lindo, del que deriva su narcisismo, su carácter vanidoso y su dudosa virilidad. Un último y trascendental rasgo del Marqués es la ausencia del sentido del honor, elemento fundamental en la dramaturgia áurea. Del resto de los personajes 'serios', se dedican interesantes comentarios a Enrique (con características totalmente opuestas a las de su hermano; discreto y valiente) y a Porcia, la dama, que refleja los tópicos esenciales en este tipo de personajes de belleza y discreción. Una característica importante de Porcia, resaltada por el editor, es que se muestra consciente de su dignidad como mujer (pp. 44-45). Quiero mencionar, a título personal, a Copete, criado-bufón, en palabras del Marqués (v. 358) al que el editor define como «carácter cómico 'serio'» (p. 46), fiel, desinteresado, creador de enredos y transmisor de reflexiones serias.

El siguiente apartado de la introducción se dedica a la «escenografía y escenificación», aspectos de la representación que afortunadamente cada vez reciben más atención por parte de los estudiosos del teatro áureo español. El texto de Cubillo presenta pocas acotaciones, algo habitual en las comedias del almagreño, por ejemplo en La honestidad defendida de Elisa Dido, reina y fundadora de Cartago. El autor parece haber preferido, en su lugar, las didascalias implícitas que suponen un grado de información mayor para el espectador/lector de la comedia (pp. 50-51). Cierra este apartado un análisis muy importante en la concepción teatral del dramaturgo almagreño: los apartes.

A continuación, se estudia detalladamente la versificación que se inicia con la sinopsis métrica, que constata el predominio del romance con más de un $60 \%$. Acompaña esta sección con unas «observaciones» en las que se analiza la versificación utilizada en cada uno de los cuadros y escenas en los que está dividida la comedia, llegando a la conclusión de que «la polimetría, con preferencia del romance, viene determinada por los cambios de jornadas, cuadros o escenas, pero a veces parece estar relacionada con la entrada en diálogo de algún personaje o con la introducción de algún motivo que conduce al progreso de la intriga» (p. 58).

La trasmisión textual del teatro de Cubillo se basa para algunas de sus comedias en la antología que el mismo dramaturgo editó con el título de El enano de las Musas (1654). Sin embargo, El señor de las Noches Buenas, presenta la particularidad de la existencia de una impresión anterior en una colección titulada Flor de las mejores doce comedias de los mayores ingenios de España, sacadas de sus verdaderos originales (1652). En esta primera colección la comedia se atribuye erróneamente a Antonio Hurtado de Mendoza, circunstancia a la que hace mención el dramaturgo almagreño en El enano, que se refiere a la atribución a Hurtado de Mendoza, afirmando la malicia de esta autoría, que «deuió de ser malicia de algún émulo mío». Se ha localizado también una copia manuscrita (ca. 1658) que reitera el error de autoría de Flor de las mejores doce comedias; una suelta que pudo ser imprimida alrededor de 1730. En el siglo XIX fue publicada en varias colecciones: Comedias escogidas de don Álvaro Cubillo de Aragón (1826); Dramaturgos posteriores a Lope de Vega (BAE, 1858) y Teatro selecto antiguo y moderno, nacional y 
extranjero (1867). Ya en el siglo xx tenemos la ya citada edición de Valbuena Prat junto con Las muñecas de Marcela en 1928. Tras un minucioso estudio de las variantes contenidas en las versiones del siglo XVII y la suelta de la centuria siguiente, Domínguez Matito llega a la conclusión de que las dos impresiones del siglo XVII (El enano y Flor) derivan de un subarquetipo «a partir del cual se separan en algunas lecturas divergentes» (p. 74). La suelta dependería más directamente de El enano, mientras que el manuscrito de 1658 «parece proceder de un subarquetipo distinto» (p. 74). De acuerdo con este análisis el editor ha tomado como texto base para su edición la versión de El enano, el codex optimus.

Cierran la introducción los criterios seguidos para editar el texto que siguen los adoptados en las de los dramaturgos contemporáneos de Cubillo: modernización de grafías, acentuación y puntuación, etc.; y una completa bibliografía que reúne los principales estudios publicados sobre el dramaturgo, así como la utilizada en el aparato de notas.

Como es el caso en cualquier edición de un texto clásico la parte más importante la constituye el texto. En este caso, podemos afirmar sin ningún tipo de exageración que nos hallamos ante una versión muy cuidada y limpia de la comedia de Cubillo; únicamente he encontrado una errata sin la menor importancia en el verso 367: «si todo mi hicieras de oro». La anotación es muy completa, informativa y nada engorrosa, algo que es de agradecer en una época en la que algunos editores llenan las notas interpretativas con alusiones eruditas que no aportan nada al entendimiento del texto anotado, pero que sí parecen servir para el lucimiento personal. No es este el caso del editor, que transita por los ámbitos eruditos necesarios para situar al autor en su espacio cultural sin hacer molesta su consulta al lector del siglo XXI. Por deformación profesional cancioneril he echado en falta en la nota a los versos 1128-1134 en el análisis del «enamoramiento de oídas» la referencia al amour de lonh de la poesía trovadoresca, que siguieron los poetas castellanos del siglo XV y los poetas y dramaturgos de los siglos XVI y XVII.

En conclusión, en este proceso de recuperación del teatro español del Siglo de Oro, la presente edición, así como el resto de la labor desarrollada por Domínguez Matito sobre Cubillo, supone un paso fundamental en el conocimiento de un dramaturgo poco leído y estudiado, pero que merece mucha más atención si queremos valorar en toda su extensión el fenómeno teatral del Barroco español. 